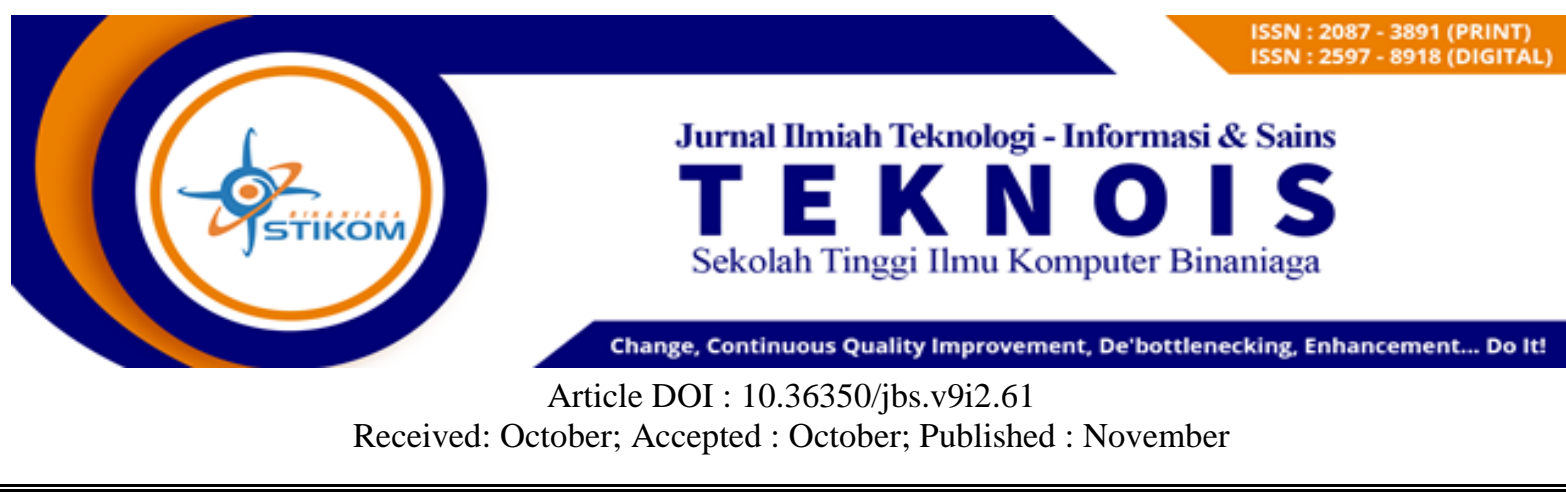

\title{
Penerapan system pakar pada aplikasi bengkel online berbasis android untuk meningkatkan pelayanan bengkel
}

\author{
Syafrial ${ }^{1 *}$, Fauzi $^{2}$ \\ ${ }^{1}$ Sistem Informasi/STIKOM Binaniga \\ Email: syafrial@stikombinaniaga.ac.id \\ ${ }^{2}$ Sistem Informasi/STIKOM Binaniga \\ Email: fauzidhoank@gmail.com
}

\begin{abstract}
Motorized vehicles are the transportation media needed today because moving motorized vehicles make time and energy efficiency. Motorbikes are an ideal transportation medium for traversing increasingly crowded cities. Along with the increasing number of vehicles caused by the community's need for transportation, this means that it is directly proportional to the community's need for vehicle maintenance services such as garage services. At present the workshop is required to have a different mindset and operational concepts. Excellent service quality for the survival of the company. Good service quality, will satisfy and then make customers become loyal to continue to use these services. Therefore, to get better services, interactive media are needed to increase the level of customer satisfaction. The composer uses the certainty factor system method in the android-based online workshop application so that it can help damage anything discussed on the vehicle and provides solutions obtained from the android-based online workshop application service with the optimal level of customer satisfaction so that it will be able to create loyalty for customers of transportation vehicle users.
\end{abstract}

Keywords: Expert System; Certainty Factor; android

\section{ABSTRAK}

Kendaraan bermotor merupakan media transportasi yang dibutuhkan saat ini karena kendaraan bermotor membuat efisiensi waktu dan tenaga. Sepeda motor merupakan media trasportasi yang ideal untuk melintasi kota yang semakin padat. Seiring dengan bertambaah pesatnya jumlah kendaraan bermotor yang disebabkan karena kebutuhan masyarakat akan sarana transportasi, maka hal tersebut tentunya berbanding lurus dengan kebutuhan masyarakat akan jasa perawatan kendaraan bermotor seperti jasa bengkel. Pada masa kini bengkel dituntut untuk mempunyai pola pikir dan konsep operasional yang berbeda. Kualitas pelayanan yang baik sangat berpengaruh untuk kelangsungan hidup perusahaan. Kualitas pelayanan yang baik, akan merasa puas sehingga membuat pelanggan menjadi loyal untuk tetap menggunakan layanan jasa tersebut. Oleh karena Itu untuk Memberikan pelayanan yang lebih baik lagi dibutuhkan media yang interkatif untuk menambah tingkat kepuasan pelanggan. Penyusun menerapkan metode sistem pakar certainty factor pada aplikasi bengkel online berbasis android sehingga pelanggan dapat mengetahui kerusakan apa saja yang dialami pada kendaraannya serta memberi solusi yang didapat dari pelayanan aplikasi bengkel online 
berbasis android dengan tingkat kepuasan pelangan yang optimal sehinga akan mendorong tercipta loyalitas bagi pelanggan pengguna kendaraan bermotor.

Keywords: Expert System; Certainty Factor; android

\section{A. PENDAHULUAN}

\section{Latar Belakang}

Sepeda motor merupakan media trasportasi yang ideal untuk melintasi kota yang semakin padat, dengan harga yang terjangkaau oleh masyarakat dan konsumsi bahan bakar yang rendah membuat kendaraan tipe ini menjadi pilihan utama bertransportasi. Seiring dengan bertambaah pesatnya jumlah sepeda motor yang disebabkan karena kebutuhan masyarakat akan sarana transportasi, maka hal tersebut tentunya berbanding lurus dengan kebutuhan masyarakat akan jasa Perawatan sepeda motor seperti jasa bengkel.

Usaha bengkel sepeda motor adalah usaha yang melakukan perbaikan sepeda motor agar dapat kembali berjalan dengan baik sesuai dengan keinginan pemilik atau bentuk asli dari sepeda motor tersebut. Secara umum fungsi bengkel adalah melayani kerperluan teknis dari para pelanggannya. Ini berarti bahwa perbaikan kendaraan adalah tugas sebuah bengkel dan hanya berlangsung jika pelanggan menemui kesulitan dengan kendaraannya.

Kualitas pelayanan yang baik sangat berpengaruh untuk kelangsungan hidup perusahaan. Kualitas Pelayanan yang baik, akan merasa puas sehingga membuat pelanggan menjadi loyal untuk tetap menggunakan layanan jasa tersebut. Demikian halnya, terciptanya tingkat kepuasan pelanggan yang optimal mendorong terciptanya loyalitas dibenak pelanggan yang merasa puas tersebut (Oktaviani Ramenusa,2013).

Ukuran suatu pelayanan baik barang atau jasa menjadi sorotan perhatian bagi para konsumen. Berbeda dengan barang, penilaian konsumen terhadap kualitas jasa terjadi selama proses penyampaian tersebut. Setiap kontak yang terjadi antara penyedia jasa dengan konsumen merupakan gambaran mengenai suatu" momenth of trut", yaitu suatu peluang untuk memuaskan atau tidak memuaskan konsumen (Farida Jasfar, 2005). Dalam hal ini konsumen tidak saja melihat dari segi sarana dan prasarana yang di sediakan, tetapi juga kenyamanan dalam pelayanan yang didapatkan oleh konsumen tersebut apakah sesuai yang di harapkan. Oleh karena itu kenyamanan layanan menjadi faktor penting dalam memberikan kepuasan kepada pelanggan terutama pada perusahaan jasa.

Perkembangan teknologi dan sistim informasi, komunikasi berkembang menjadi suatu bisnis tersendiri. Teknologi informasi dapat diterapkan pada semua jenis usaha dan telah menjadi kebutuhan dasar mulai dari perusahaan kecil sampai perusahaan besar bahkan sekalipun. Jadi sudah saatnya setiap perusahaan menggunakan Peranan Teknologi untuk mulai menerapkan dalam usaha mereka agar dapat bersaing dengan perusahaan lain. Kini banyak perusahaan yang berupaya untuk mengembangkan strategi yang efektif guna membangun, mempertahankan dan meningkatkan loyalitas pelanggannya

\section{Permasalahan}

Kebutuhan masyarakat akan sarana transportasi tentunya berbanding lurus dengan kebutuhan masyarakat akan jasa service sepeda motor seperti jasa bengkel. Baiknya pengguna sepeda motor selalu mengecek kondisi kendaraan sebelum dipergunakan. Namun sering kali hal tersebut diabaikan oleh sebagian pengguna sepeda motor, sehingga pada saaat sepeda motor akan digunakan terjadi ganguan-ganguan dan ketidaknyamanan dalem mengendarai sepeda motor tersebut. 


\section{Tujuan}

Pemilik dapat mengetahui lebih dini tentang kondisi sepeda motor sebelum terjadi kerusakan dan untuk meningkatkan pelayanan bengkel dengan membuat aplikasi bengkel online dengan penerapan sistem pakar guna mendorong terciptanya loyalitas pelanggan.

\section{B. METODE}

\section{Prosedur Pengembangan}

Prosedur pengembangan merupakan proses urutan pekerjaan mulai dari analisa kebutuhan hinga sistem dapat beroperasi dengan baik. Pada penelitian ini metode prototype digunakan untuk proses pengembangan dengan langkah-langkah pengembangan sebagai berikut :

a. Pengumpulan dokumen yang dibutuhkan

b. Perancangan kebutuhan berupa use case diagram, proses bisnis, class diagram, arsitektur teknologi, infrastruktur teknologi dan perangkat lunak yang dibutuhkan.

\section{Analisa Pengembangan}

Salah satu metode yang digunakan adalah faktor kepastian (certainty factor). Faktor kepastian diperkenalkan oleh Shortliffe Buchanan dalam pembuatan MYCIN (Wesley, 1984). Certainty factor (CF) merupakan nilai parameter klinis yang diberikan MYCIN untuk menunjukkan besarnya kepercayaan. Ada 2 macam faktor kepastian yang digunakan, yaitu faktor kepastian yang diisikan oleh pakar bersama dengan aturan dan faktor kepastian yang diberikan oleh pengguna. Dengan menggali dari hasil wawancara dengan pakar. Nilai $\mathrm{CF}($ rule) didapat dari interpretasi "term" dari pakar menjadi nilai MD/MB tertentu.

Tabel 1. Certain Term MD/MB

\begin{tabular}{|l|l|}
\hline Keterangan & Interval \\
\hline Tidak Tahu/Tidak Ada & $0.00-0.29$ \\
\hline Mungkin & $0.30-0.49$ \\
\hline Kemungkinan Besar & $0.50-0.69$ \\
\hline Hampir Pasti & $0.70-0.89$ \\
\hline Pasti & $0.90-1.00$ \\
\hline
\end{tabular}

Menggunakan metode perhitungan. Faktor kepastian (certainty factor) menunjukkan ukuran kepastian terhadap suatu fakta atau aturan. Notasi Faktor Kepastian

Salah satu contoh aplikasi sistem pakar yang menggunakan metode certainty factor (CF) untuk menangani ketidakpastian adalah MYCIN, sistem pakar untuk mendiagnosa infeksibakteri pada darah. Certainty factor didefinisikan sebagai berikut (Hartati dan Iswanti,2013):

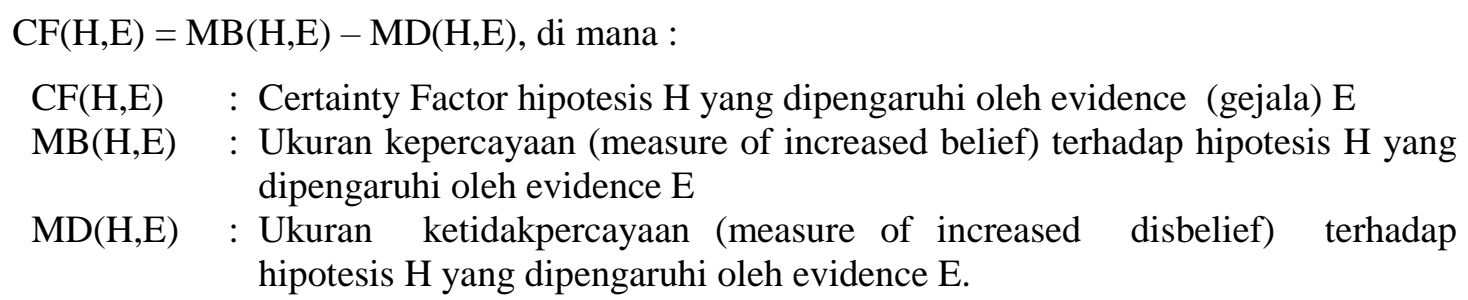

Pada basis pengetahuansistem pakar ini premis adalah gejala yang terlihat pada Motor, dan konklusi adalah identifikasi kerusakan pada Motor, sehingga bentuk pernyataannyaadalah JIKA [gejala] MAKA [Klasifikasi].Bagian premis dalam aturan produksi dapat memilikilebih dari satu proposisi yaitu berarti pada sistem pakar inidalam satu kaidah dapat memiliki lebih dari satu gejala.Gejalatersebut dihubungkan dengan menggunakanoperator logika DAN.

Bentuk pernyatannya adalah :

JIKA [gejala 1] DAN [gejala 2] DAN [gejala 3] MAKA [Klasifikasi] 


\section{HASIL DAN PEMBAHASAN}

\section{Hasil}

Hasil penelitian pengembangan akan diuraikan sesuai dengan model pengembangan, berikut tahap-tahap yang dilakukan :

a. Pengumpulan dokumen yang dibutuhkan

Pada Tahap ini dilakukan pengumpulan kebutuhan System dengan cara mendengar keluhan dari pelanggan. Untuk membuat System yang sesuai kebutuhan maka harus diketahui terlebih dahulu bagaimana system yang sedang berjalan untuk kemudian mengetahui masalah yang terjadi.

Untuk mengetahui sejauh mana gejala yang terjadi pada sepeda motor, tentunya dibutuhkan pengetahuan dan pengalaman. Dibawah ini merupakan bahagian dari pengetahuan dan pengalaman yang diperoleh dari mekanik service sepeda motor.

Tabel 2 : Daftar Gejala Sepeda motor

\begin{tabular}{|c|c|c|}
\hline Kode & Nama Gejala & Keterangan \\
\hline G001 & Tenaga yang dihasilkan berkurang & Piston \\
\hline G002 & Keluar asap putih pada kenalpot & Piston \\
\hline G003 & Suara kasar pada kepala silinder & Piston \\
\hline G004 & Tenaga yang dihasilkan berkurang & Stang seher \\
\hline G005 & getaran mesin sangat terasa & Stang seher \\
\hline G006 & Suara berisik ketika gas di rpm rendah & Stang seher \\
\hline G007 & Mesin brebet saat dipacu & Stang seher \\
\hline G008 & Tenaga yang dihasilkan berkurang & Rantai keteng \\
\hline G009 & Mesin tidak stabil/tersendat sendat & Rantai keteng \\
\hline G010 & Suara kasar pada mesin bagian kiri ketika suhu dingin & Rantai keteng \\
\hline G011 & Tenaga yang dihasilkan berkurang & Kopling \\
\hline G012 & Saat gas ditarik motor tidak mau langsung berjalan & Kopling \\
\hline G013 & Suara mesin tidak lepas & Kopling \\
\hline G014 & Slip saat melakukan perpindahan gigi & Kopling \\
\hline G015 & Sulit saat melakukan perpindahan gigi & Transmisi \\
\hline G016 & Pedal transmisi lose & Transmisi \\
\hline G017 & Pedal tidak mau berpindah transmisi (ditambah atau kurang) & Transmisi \\
\hline G018 & Gas tidak stationer & Klep \\
\hline G019 & Keluar asap hitam pada knalpot & Klep \\
\hline G020 & Bbm boros & Klep \\
\hline G021 & Oli mesin cepat berkurang & Klep \\
\hline G022 & Lampu indikator pada speedometer berkedip berkali kali & Injeksi \\
\hline G023 & Tampilan suhu mesin pada speedometer tidak stabil & Injeksi \\
\hline G024 & Motor tidak langsam & Injeksi \\
\hline G025 & Penggunaan bahan bakar semakin boros & Injeksi \\
\hline G027 & Tidak ada percikan api pada busi & Busi \\
\hline G028 & Mesin meletus letus saat berjalan & Busi \\
\hline G029 & Mesin sulit dihidupkan & Koil \\
\hline G030 & Percikan api pada busi berwarna kemerahan & Koil \\
\hline
\end{tabular}


Volume 9 Number 2 November 2019 Page. 32-43

Journal Homepage : http://teknois.stikombinaniaga.ac.id/index.php/JBS

DOI Link : http://doi.org/10.36350/jbs.v9i2

\begin{tabular}{|l|l|l|} 
G031 & Mesin tiba tiba mati ketika sedang berjalan & Koil \\
\hline G032 & Mesin sulit dihidupkan & Cdi \\
\hline G033 & Mesin brebet di rpm tinggi & Cdi \\
\hline G034 & Percikan api pada busi pendek & Cdi \\
\hline G035 & Busi sering mati & Cdi \\
\hline G036 & Mesin tidak bisa dihidupkan & Spull \\
\hline G037 & Lampu lampu (sign,speedometer,headlamp,dll) mati & Spull \\
\hline G038 & Bohlam lampu sering putus atau mati & Kiprok \\
\hline G039 & Aki cepat soak & Kiprok \\
\hline G040 & Mesin tiba tiba mati ketika sedang berjalan & Kiprok \\
\hline G041 & Lampu indikator pada speedometer tidak menyala & Aki \\
\hline G042 & Elektrik starter tidak berfungsi & Aki \\
\hline G043 & Lampu signal (rem,sign, dan head lamp) redup & Aki \\
\hline G044 & Klakson tidak bersuara & Aki \\
\hline
\end{tabular}

b. Perancangan kebutuhan sistem.

1) Use Case Diagram

Terdapat satu actor dalam proses system ini. User dapat melakukan Pemesanan Barang ataupun ingin mengetahui kerusakan. Sebelum melakukan proses Pemesanan dan mengetahui kerusakan, user harus melakuakan Login terlebih dahulu.

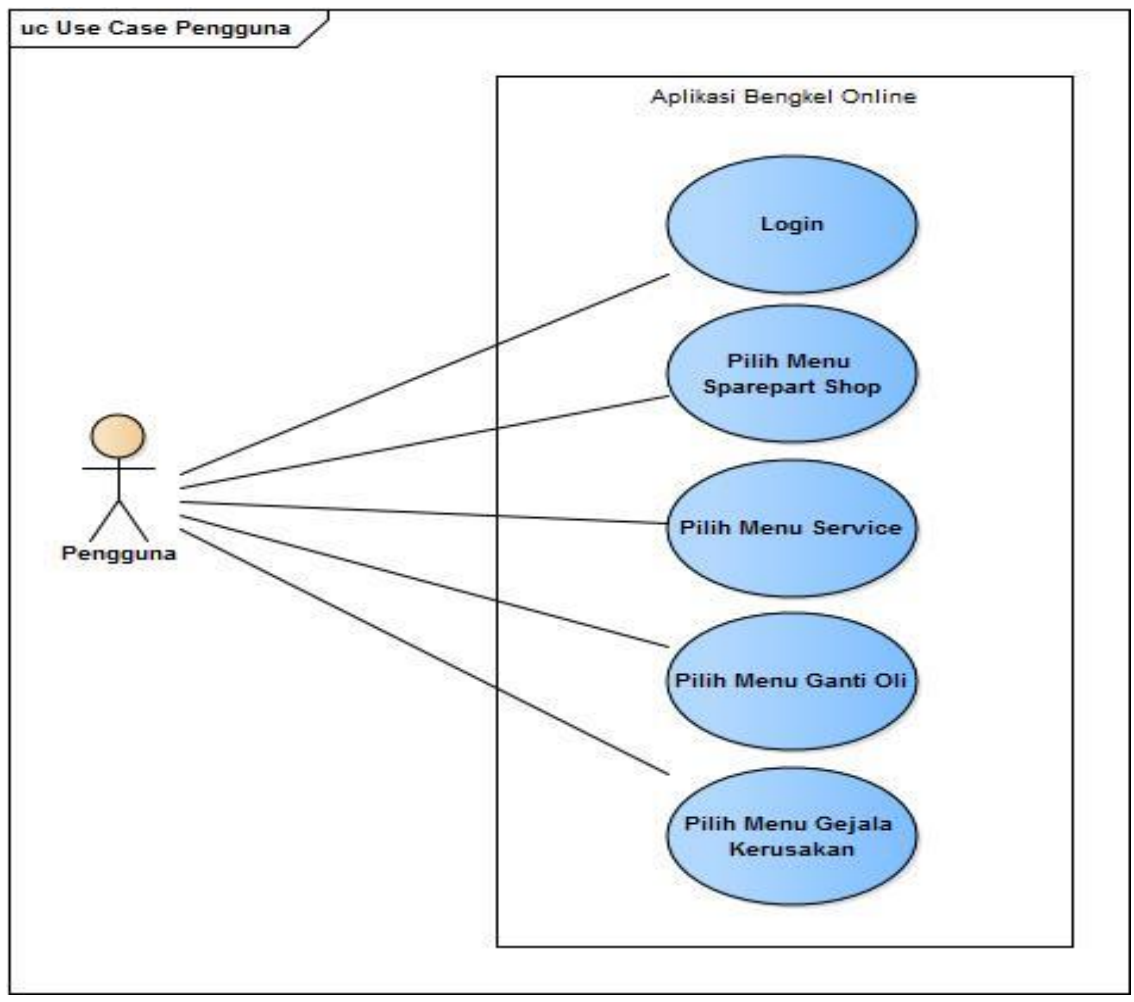

Gambar 1. Use case diagram

2) Proses Bisnis

Proses Bisnis ini merupakan proses dimana User dapat melakukan Pemesanan barang maupun mengidentifikasi gejla kerusakan motor. 
Volume 9 Number 2 November 2019 Page. 32-43

Journal Homepage : http://teknois.stikombinaniaga.ac.id/index.php/JBS

DOI Link : http://doi.org/10.36350/ibs.v9i2
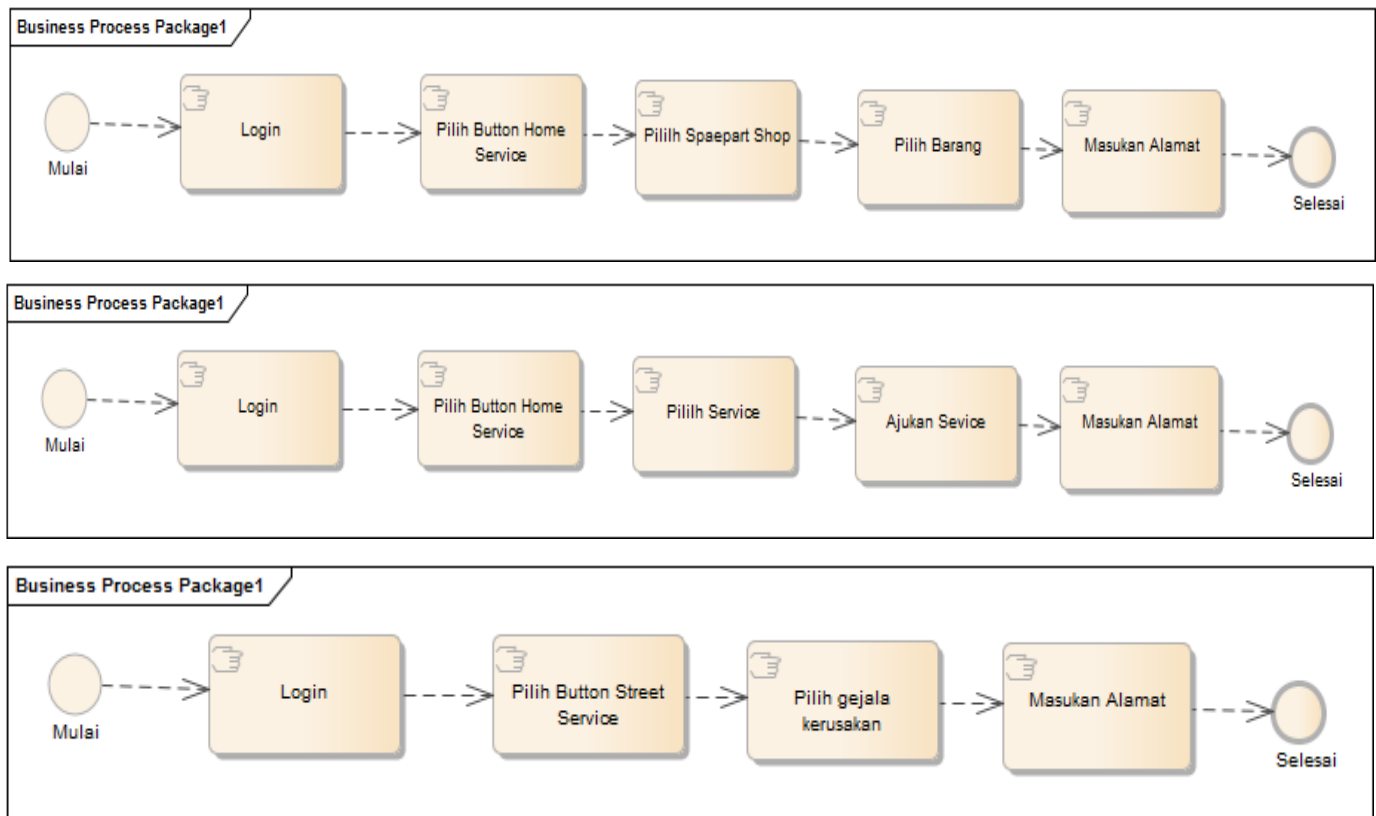

Gambar 2. Proses Bisnis

3) Class Diagram

Class diagram adalah diagram yang digunakan untuk menampilkan beberapa kelas yang ada dalam sistem perangkat lunak yang dikembangkan. Class Diagram menunjukkan hubungan antar class dalam sistem yang dibangun dan bagaimana mereka saling berkolaborasi untuk mencapai tujuan.

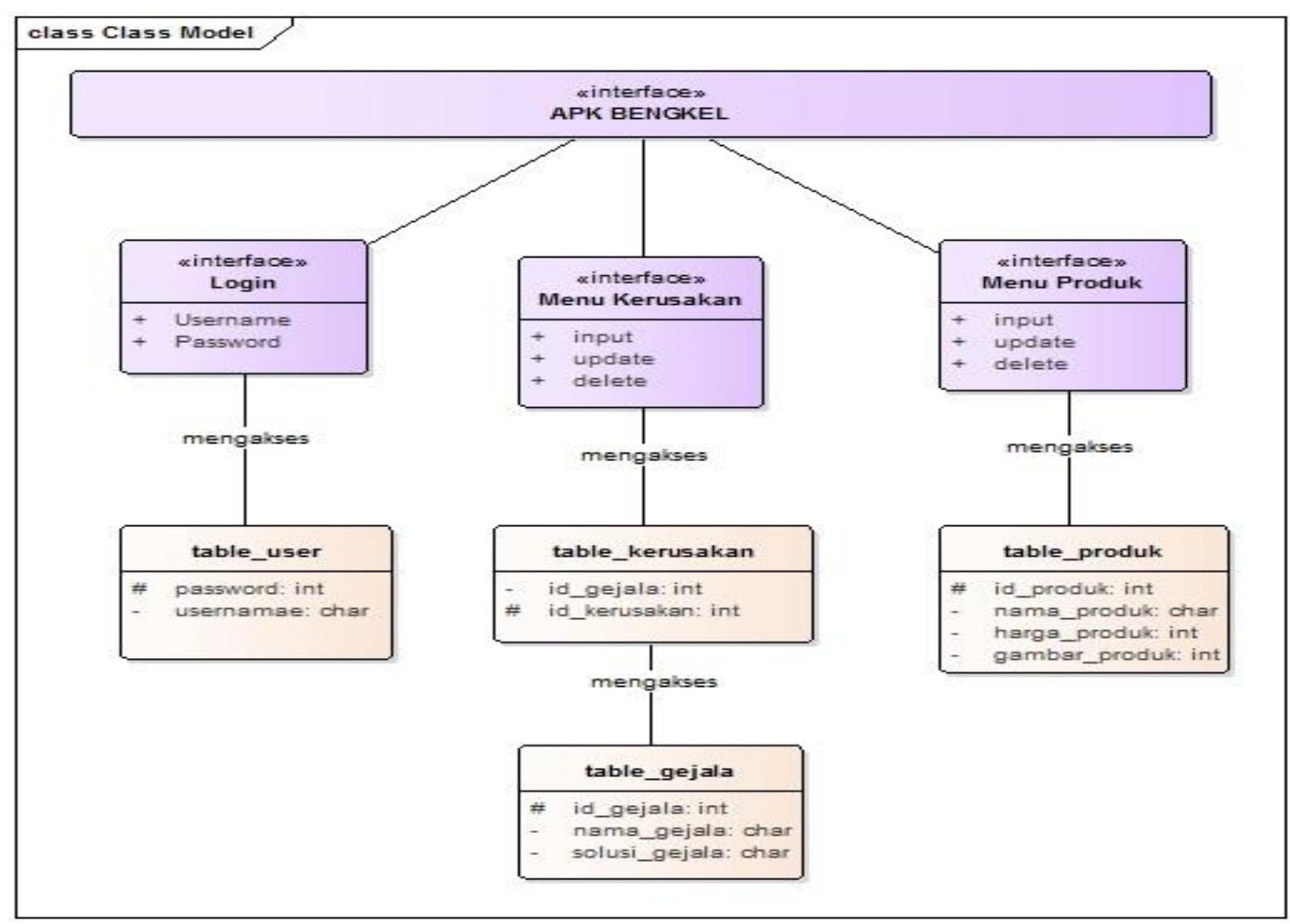

Gambar 3. Class Diagram 
4) Arsitektur Teknologi

Desain fisik dari perangkat lunak, sistem yang dikembangkan akan mampu diakses pada platform, laptop, dan smartphone android. Berikut gambar 4.3 skema arsitektur teknologi yang dikembangkan.

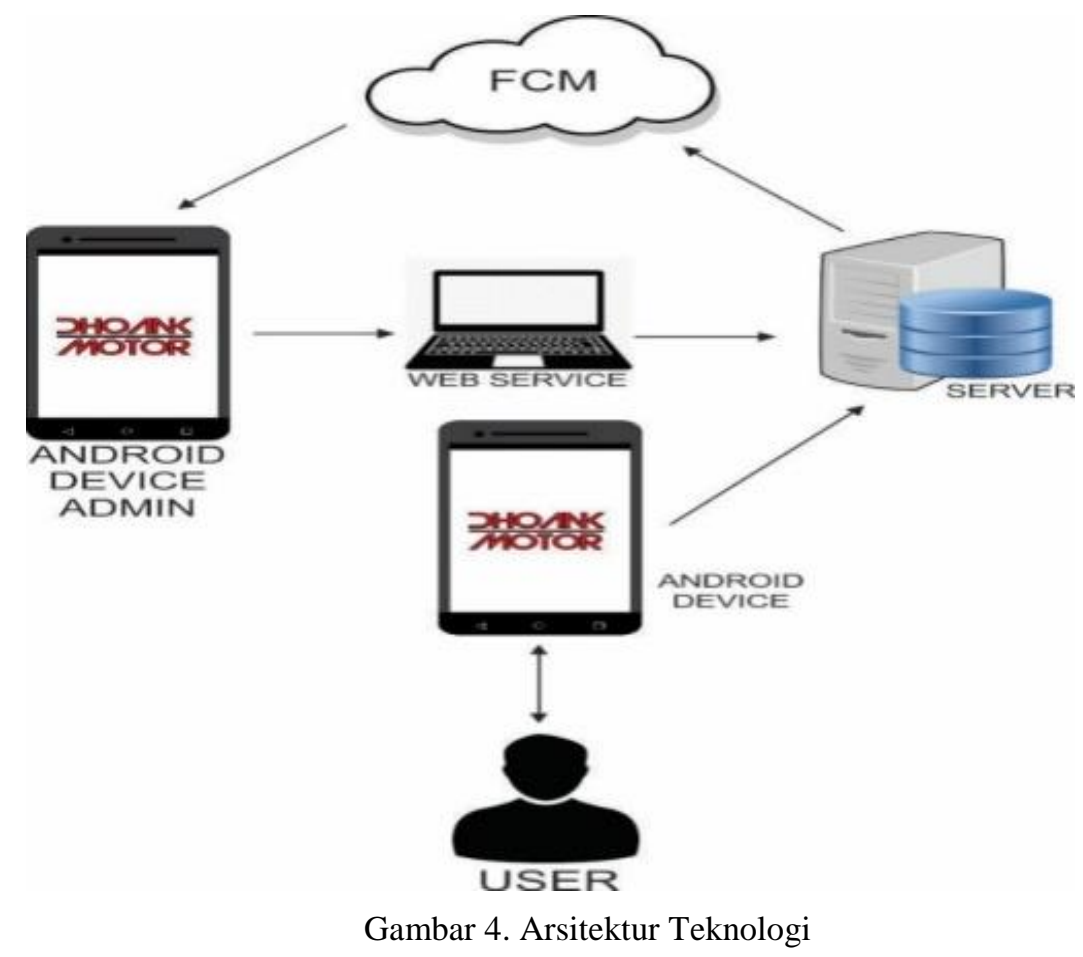

5) Infrastruktur Teknologi

a) Hardware

Perangkat keras yang dibutuhkan dan bagaimana keterhubungannya agar dapat saling berkomunikasi. Deskripsi berupa Satu buah PC untuk web services dan database, Smartphone untuk penggunaan aplikasi mobile dengan minimum spesifikasi Layar 5 Inch, RAM 2 GB, Processor Quad-core 1.2 GHz Cortex-A53, Android OS Android 5.1.1 Lollipop

b) Wireless access point/simcard (quota data)Software

Kerangka aplikasi dari produk pengembangan dibuat dengan metode client-server dimana aplikasi dan database terpisah, smartphone yang meminta (request) data dan satu komputer server, yaitu komputer khusus yang menyimpan data yang kemudian dapat mengirimkan permintaan data ke client.

Berikut beberapa komponen yang ada pada PC Server :

$>$ Operating System (OS), yaitu sistem operasi perangkat lunak komputer untuk mengontrol dan manajemen operasi-operasi dasar komputer baik yang berhubungan dengan perangkat keras ataupun perangkat lunak seperti menjalankan software aplikasi yang biasa digunakan sehari-sehari, contoh MS Word, MS. Excel, dan program lainnya.

$>$ Web server, software yang memberikan layanan berbasis data dan berfungsi menerima permintaan HTTP atau HTTPS dari klien atau web browser. Beberapa contoh web server yaitu, Apache, Microsoft Window Server 2003 Internet Information Services (IIS), Sun Java System Web Server, dan lainnya. 
$>$ MYSQL, sebuah software sistem manajemen database relasional (RDBMS: Relational Data Base Manajement System) yang banyak digunakan karena kemudahannya dan tidak berbayar.

$>$ PHP, yaitu bahasa pemrograman yang digunakan secara luas untuk penanganan pembuatan dan pengembangan aplikasi berbasis website yang juga bisa digunakan bersamaan dengan format HTML (bahasa markup). Php kependekan dari PHP Hypertext Prepocessor.

$>\quad$ Web Services, merupakan software aplikasi sekumpulan data (database) yang dapat diakses secara remote oleh berbagai perangkat yang berbeda platform ataupun sistem operasi dengan sebuah perantara tertentu. Web services biasa juga disebut dengan sebutan Web API (Application Programming Interface), dalam hal ini hubungan antara klien dan server tidak terjadi secara langsung. Hubungan antara klien dan server dijembatani oleh file web API dalam format tertentu. Beberapa format API seperti JSON, XML, REST, dan lainnya.

Smartphone (klien) terdapat dua komponen, sebagai berikut :

$>$ Operating System (OS), sistem operasi android yang dikembangkan oleh Google untuk perangkat ponsel cerdas.

> Aplikasi Manajemen dan Teknisi, aplikasi (apps) yang dibangun untuk dapat digunakan dalam smartphone berbasis android, dikembangkan dapat mengelola source (hardware) yang ada pada ponsel cerdas seperti, memory, kamera, GPS, dan lain sebagainya.

$>$ Realm adalah sebuah library database untuk perangkat mobile smartphone yang menggunakan konsep tanpa skema (schemaless) atau yang biasa disebut dengan konsep NoSQL. Realm biasanya banyak digunakan untuk penyimpanan database sementara pada platform Android ataupun iOS, dan karena kemudahan serta performa baca dan tulis yang memang lebih baik dari database mobile lainnya

6) Perangkat lunak

Dalam pengembangan penelitian terdapat beberapa komponen perangkat lunak yang mendukung jalannya sistem aplikasi yang dikembangkan, diantaranya :

a) XAMPP, sebuah software web server, terdiri dari Apache, MYSQL, PHP, dan Perl.

b) JDK (JavaDevelopment Kit) merupakan perangkat lunak yang digunakan untuk kompilasi dari kode java ke bytecode yang dapat dimengerti dan dijalankan oleh JRE. JRE (Java Runtime Environment) merupakan perangkat lunak yang digunakan untuk menjalankan aplikasi yang dibangun menggunakan java.

c) SDK (Software Development Kit)merupakan tools bagi para programmer yang ingin mengembangkan aplikasi berbasis google android. Android SDK mencakup seperangkat alat pengembangan yang komprehensif. Android SDK terdiri dari debugger, libraries, handset emulator, dokumentasi, contoh kode, dan tutorial.

d) Android Studio merupakan subset perangkat lunak untukperangkat mobile yang meliputi system operasi, middleware, dan aplikasi inti yang dirilis oleh Google. Android adalah system operasi bergerak (mobile operating system).

e) Firebase adalah BaaS (Backend as a Service) yang saat ini dimiliki oleh Google. Firebase ini merupakan solusi yang ditawarkan oleh Google untuk mempermudah pekerjaan Mobile Apps Developer. Dengan adanya Firebase, apps developer bisa fokus mengembangkan aplikasi tanpa harus memberikan effort yang besar untuk urusan backend. 


\section{Pembahasan}

Penggunaan Metode CertaintyFactor untuk melakukan identifikasi kerusakan pada sepeda motor dengan memasukkan gejala yang terjadi pada sepeda motor pengguna yang kemudian dilakukan proses identifikasi menggunakan algoritmaCertainty Factor.

Dalam basis pengetahuan ini digunakan kaidah produksi sebagai sarana untuk representasi pengetahuan.Kaidah produksi dituliskan dalam bentuk pernyataan JIKA[premis] MAKA [konklusi]. Pada basis pengetahuan sistem pakar ini premis adalah gejala yang terlihat pada Motor, dan konklusi adalah identifikasi kerusakan pada sepeda motor, sehingga bentuk pernyataannyaadalah JIKA [gejala] MAKA [Klasifikasi].

Bagian premis dalam aturan produksi dapat memiliki lebih dari satu proposisi yaitu berarti pada sistem pakar ini dalam satu kaidah dapat memiliki lebih dari satu gejala. Gejala tersebut dihubungkan dengan menggunakan operator logika DAN. Bentuk pernyatannya adalah

JIKA [gejala 1]

DAN [gejala 2]

DAN [gejala 3]

MAKA [Klasifikasi]

Adapun contoh kaidah Sistem Pakar Identifikasi Gejala Kerusakan Motor adalah :

JIKA Keluar Asap Putih Pada Knalpot

DAN Suara Kasar Pada Kepala Silinder

MAKA Kerusakan Pada Piston Kit

Berikut Ini studi Kasus yang diimplementasikan dengan rumus hitung manual.

a. Piston / Tenaga yang dihasilkan Berkurang

$\mathrm{CF}[\mathrm{H}, \mathrm{E}] 1=\mathrm{MB}-\mathrm{MD}$

$\mathrm{CF}[\mathrm{H}, \mathrm{E}] 1=0.75-0.25$

$\mathrm{CF}[\mathrm{H}, \mathrm{E}] 1=0.5$

b. Piston/ keluar Asap Putih Pada Kenalpot

$\mathrm{CF}[\mathrm{H}, \mathrm{E}] 2=\mathrm{MB}-\mathrm{MD}$

$\mathrm{CF}[\mathrm{H}, \mathrm{E}] 2=0.8-0.2$

$\mathrm{CF}[\mathrm{H}, \mathrm{E}] 2=0.6$

c. Piston / suara kasar pada Kepala Silinder

$\mathrm{CF}[\mathrm{H}, \mathrm{E}] 3=\mathrm{MB}-\mathrm{MD}$

$\mathrm{CF}[\mathrm{H}, \mathrm{E}] 3=0.95-0.05$

$\mathrm{CF}[\mathrm{H}, \mathrm{E}] 3=0.9$

Berdasarkan perhitungan diatas maka diambil dari nilai yang paling tinggi yaitu:

$\mathrm{CF}[\mathrm{H}, \mathrm{E}]=\mathrm{MAX}[\mathrm{CF}[\mathrm{H}, \mathrm{E}] 1, \mathrm{CF}[\mathrm{H}, \mathrm{E}] 2, \mathrm{CF}[\mathrm{H}, \mathrm{E}] 3$,

$\mathrm{CF}[\mathrm{H}, \mathrm{E}]=\mathrm{MAX}[0.5,0.6,0.9]$

$\mathrm{CF}[\mathrm{H}, \mathrm{E}]=0.9 \Rightarrow \mathrm{CF}[\mathrm{H}, \mathrm{E}] 1$

$\mathrm{CF}[\mathrm{H}, \mathrm{E}] 1$ => P1(Kerusakan Piston/Seher)

Jadi berdasarkan perhitungan diatas maka dapat didiagnosa kerusakan terjadi pada Piston/seher dengan nilai $\mathrm{CF}=0.9$

Dengan menggali dari hasilwawancara dengan pakar. NilaiCF(Rule) didapat dariinterpretasi "term" dari pakar menjadi nilai CF tertentu sepertitabel berikut :

Tabel 3. Nilai Certain Factor berdasarkan Nilai kepastian seorang Pakar

\begin{tabular}{|l|c|}
\hline \multicolumn{1}{|c|}{ Pernyataan } & Nilai \\
\hline Pasti tidak & 0.0 \\
\hline Hampir pasti & 0.1 \\
\hline Lebih mungkin & 0.2 \\
\hline Mungkin tidak & 0.3 \\
\hline Tidak tahu & 0.4 \\
\hline
\end{tabular}


Volume 9 Number 2 November 2019 Page. 32-43

Journal Homepage : http://teknois.stikombinaniaga.ac.id/index.php/JBS

DOI Link : http://doi.org/10.36350/jbs.v9i2

\begin{tabular}{|l|l|}
\hline Tidak tahu & 0.5 \\
\hline Mungkin & 0.6 \\
\hline Lebih mungkin & 0.7 \\
\hline Hampir Pasti & 0.8 \\
\hline Pasti & 0.9 \\
\hline
\end{tabular}

\section{Implementasi}

Menu Home Service adalah menu dimana user dapat memilih kategori jenis motor mMenu sparepart Shop, service rutin, dan menu ganti oli.

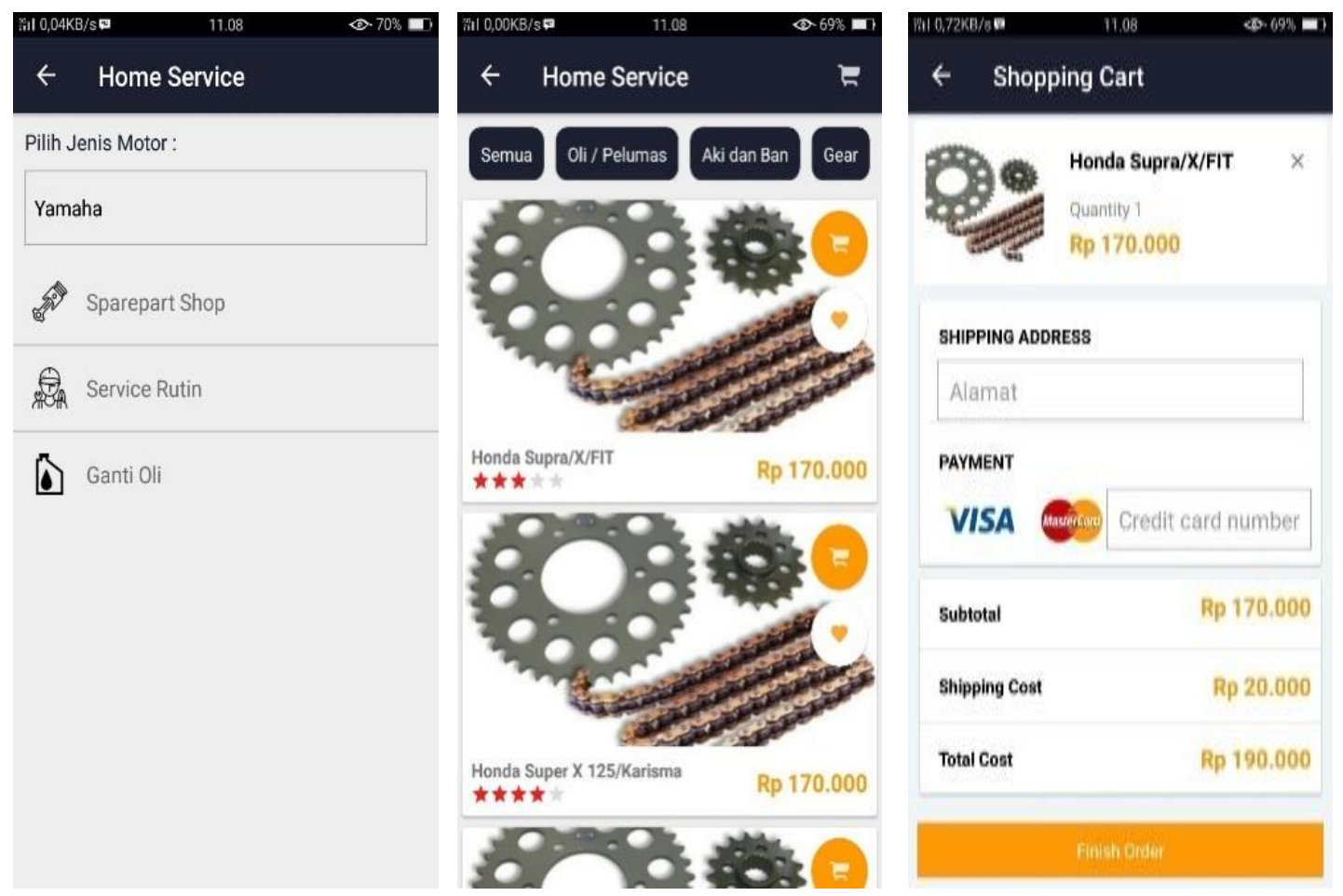

Gambar 5. Home service kategori sparepart shop.

Menu Street Service merupakan menu dimana user dapat memilih jenis kendaraan dan memilih gejala kerusakan.

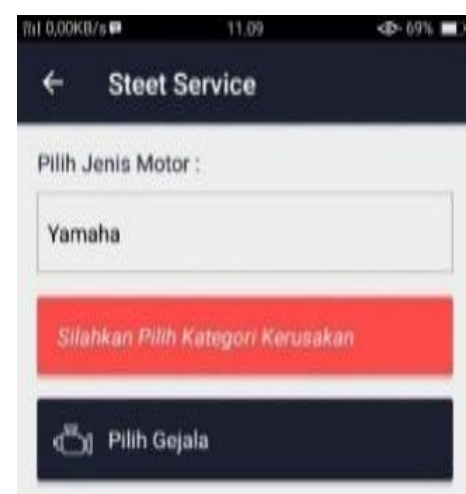

Gambar 6. Street service 
Menu Gejala Diagnosa merupakan menu yangm enampilkan gejala kerusakan yang nantinya akan dipilih oleh user, lalu setelah user memilih gejala maka akan tampil data hasil gejala yang dipilih disertai dengan kemungkinan kerusakan dan solusinya.

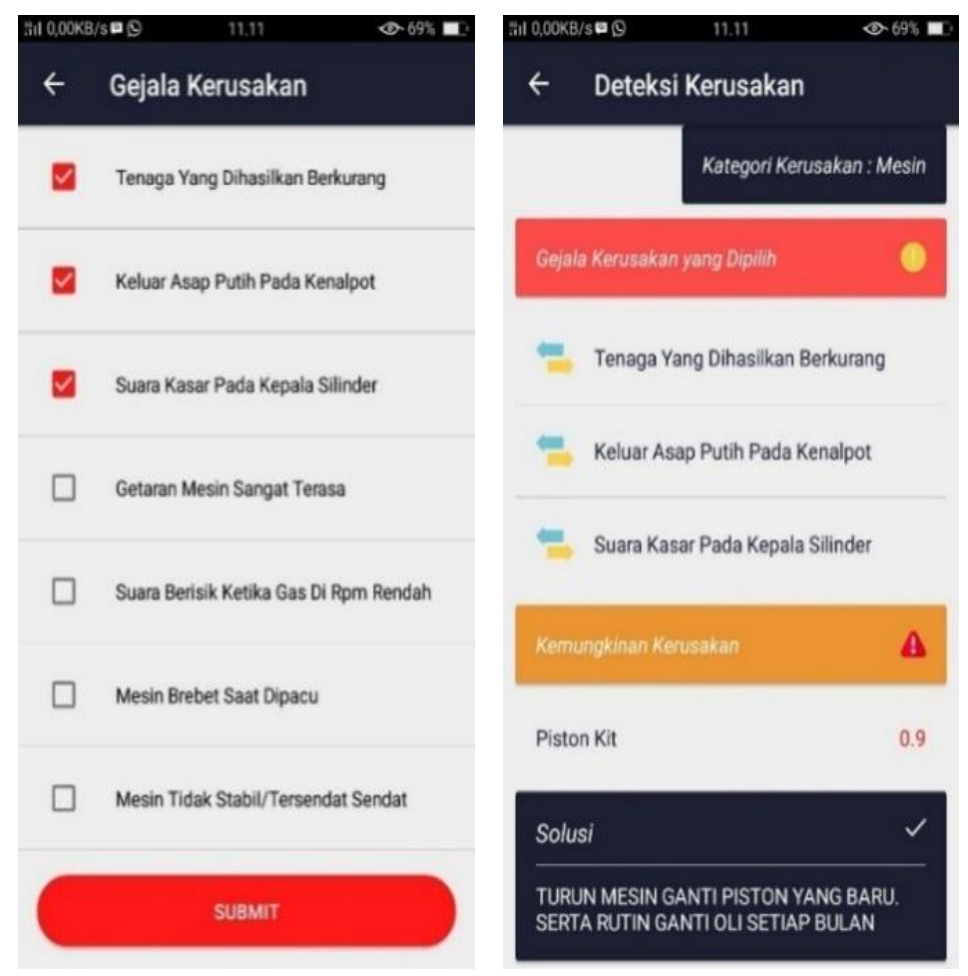

Gambar 7. Gejala Diagnosa

\section{KESIMPULAN}

Dari hasil dan pembahasan terhadap kerusakan sepeda motor dengan pendekatan sistem pakar berbasia android, dapat disimpulkan sebagai berikut :

1. Aplikasi Sistem Pakar pada Bengkel Online Berbasis Android telah berhasil di bangun dan mampu digunakan untuk mendeteksi kerusakan motor, yang meliputi proses identifikasi gejala sehingga hasil dapat sesuai dengan yang diharapkan, yaitu menghasilkan kemungkinan gejala kerusakan motor pada hasil analisis disertai dengan solusinya.

2. Faktor-faktor yang harus diperhatikan pada metode certainty factor adalah nilai keyakinan (MB) dan nilai ketidakyakinan(MD). Kedua nilai tersebut yang akan menjadi parameter awal untuk menentukan nilai certainty factor $(\mathrm{CF})$ atau nilai kepastian yang menjadi output dari metode certainty factor.

3. Aplikasi ini dapat memudahkan dan juga dapat membantu pengguna sepeda motor untuk mengetahui kerusakan yang sedang dialami oleh sepeda motornya.

\section{E. DAFTAR PUSTAKA}

[1] Arif, M. (2014). Peran Kualitas Pelayanan jasa dan Kepuasan Pelanggan Terhadap Loyalitas Pelanggan. Universitas Pembangunan Nasional Veteran Jakarta.

[2] Aryawan, I. K. (2013). Aplikasi Sistem Pakar Diagnosa kerusakan Pada Sepeda Motor 4T Menggunakan Metode Certainty Factor Berbasis Android. Volume 2,Universitas Pendidikan Ganesha Singaraja. 
[3] Irmayansyah, Irmayansyah, and Aulia Arief Firdaus. "Penerapan Algoritma C4.5 untuk Klasifikasi Penentuan Penerimaan Bantuan Langsung di Desa Ciomas" Teknois, 2018, doi:10.36350/jbs.v8i1.18.

[4] Koestanto, T. H. (2014). Pengaruh Kualitas Pelayanan Terhadap Kepuasan Pelanggan, Sekolah Tinggi Ilmu Ekonomi Indonseia (STIESIA)

[5] Maulana, A. A. (2016). Sistem Pakar Diagnosa Gangguan Mesin, Universitas Negeri Semarang.

[6] Pradhana, B. A. (2013). Perancangan Sistem Pakar Untuk Diagnosa Kerusakan Hardware Laptop Menggunakan Metode Certainty Factor, Universitas Dian Nuswantoro.

[7] Putra, G. R. (2018). Implementasi Metode Certainty Factor pada Identifikasi Kerusakan Kendaraan Bermotor Roda Dua. Jurnal Pengembangan Teknologi Informasi dan Ilmu Komputer Universitas Brawijaya.

[8] Rizky, N. I. (2016). Pembuatan Multimedia Interaktif Berbasis Android Mobile Phone Pada Pangkar Rambut Dasar (Graduasi). e- Journal Universitas Negeri Surabaya.

[9] Wijayanti, P. (2014 ). Sistem Pakar Mendiagnosa Jenis Penyakit Stroke. Jurnal Sarjana Teknik Informatika Universitas Ahmad Dahlan. 